\title{
Going Ballistic: Bullet Trajectories
}

Amanda Wade

University of South Florida

\author{
Advisors: \\ Gerald Hefley, Mathematics and Statistics \\ Scott Campbell, Chemical \& Biomedical Engineering \\ Problem Suggested By: Scott Campbell
}

Follow this and additional works at: https://digitalcommons.usf.edu/ujmm

Part of the Mathematics Commons

UJMM is an open access journal, free to authors and readers, and relies on your support: Donate Now

\section{Recommended Citation}

Wade, Amanda (2011) "Going Ballistic: Bullet Trajectories," Undergraduate Journal of Mathematical Modeling: One + Two: Vol. 4: Iss. 1, Article 5.

DOI: http://dx.doi.org/10.5038/2326-3652.4.1.5

Available at: https://digitalcommons.usf.edu/ujmm/vol4/iss1/5 


\title{
Going Ballistic: Bullet Trajectories
}

\begin{abstract}
This project seeks to answer at what angle does a gun marksman have to aim in order to hit the center of a target one meter off the ground and 1000 meters away? We begin by modeling the bullet's trajectory using Euler's method with the help of a Microsoft Excel spreadsheet solver, and then systematically search for the angle corresponding to the center of the target. It was found that a marksman shooting a target 1000 meters away and 1 meter off the ground has to aim the rifle $0.436^{\circ}$ above horizontal to hit the center.
\end{abstract}

\section{Keywords}

Euler's Method, Velocity, Projectile Motion

\section{Creative Commons License}

(c) (i) (9)

This work is licensed under a Creative Commons Attribution-Noncommercial-Share Alike 4.0 License. 


\section{TABLE OF CONTENTS}

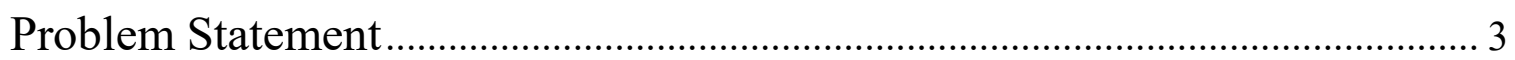

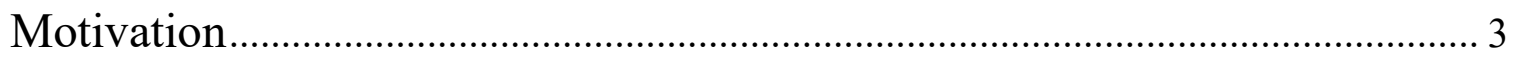

Mathematical Description and Solution Approach ............................................. 4

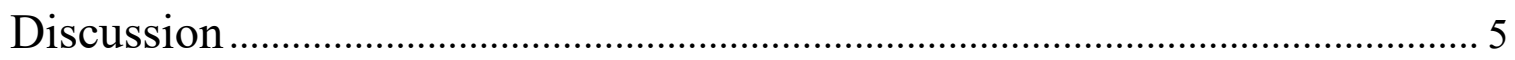

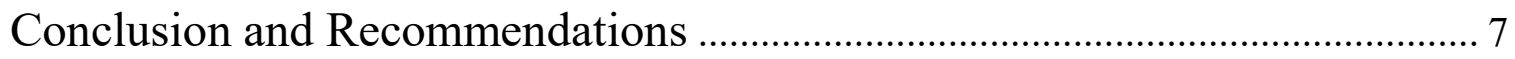

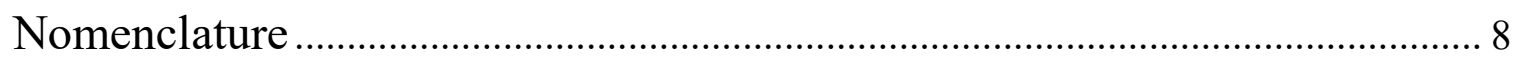

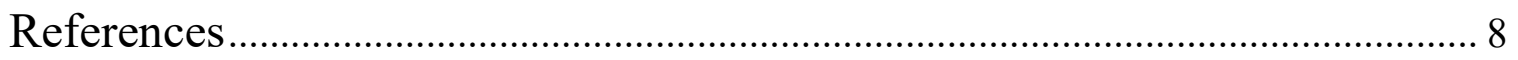

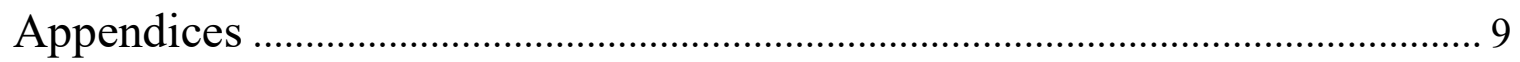




\section{PROBLEM STATEMENT}

At what angle above the horizontal does a gun marksman shooting one meter off the ground in $27.2^{\circ} \mathrm{C}$ weather; have to aim a Remington $30-06$ rifle to hit the center of a target that is 1000 meters away and one meter off the ground? Take into account air resistance and ignore the wind variable. You may assume a bullet mass of 150 grains, muzzle velocity of $887 \mathrm{~m} / \mathrm{s}$, bullet diameter of $0.008 m$ and the shooter is at sea level.

\section{MOTIVATION}

The calculation of bullet trajectories is necessary help scientist and engineers develop equipment for the United States Department of Defense, particularly Marine Corp snipers. Snipers specialize in long distance shooting, both at targets of known and unknown distances. There are many important pieces that factor into the understanding of bullet trajectories: air resistance, angle, air pressure and temperature, muzzle velocity, bullet shape and drag coefficient. All of these factors contribute to the accuracy of the bullet hitting the desired target. Snipers usually have one chance to hit their target and knowing all the above pieces can make the job easier. Scientist and engineers work together to construct simulations, to develop data that can benefit snipers in real life situations. Ballistics data also goes into the design and construction of scopes, rangefinders and different types of ammunition. 


\section{MATHEMATICAL DESCRIPTION AND SOLUTION APPROACH}

Let $x(t)$ and $y(t)$ denote the horizontal and vertical displacement of the bullet at the time $t$. Similarly define $v_{x}(t)$ and $v_{y}(t)$ to be the horizontal and vertical velocity of the bullet at the time $t$. We use $f^{\prime}(t)$ to denote the derivative of the function $f(t)$ with respect to $t$. We first use the density of air $\rho=353.03 \frac{P}{T}$ to calculate the drag,

$$
D=\frac{1}{2} \rho C A
$$

where $C=0.295$ is the drag coefficient of the bullet and $A$ is the area of the bullet head in $m^{2}$. We now use the well-known motion equations for an object moving through a gravitation field to see:

$$
\begin{gathered}
v_{x}^{\prime}(t)=-\frac{D}{M} v \cdot v_{x}(t) \\
v_{y}^{\prime}(t)=-g-\frac{D}{M} v \cdot v_{y}(t)
\end{gathered}
$$

where $M$ is the mass of the bullet in kilograms, $g$ is the acceleration due to gravity and $v$ is the magnitude of the velocity vector. Using the velocity of the bullet given in the problem we can determine our initial conditions:

$$
\begin{gathered}
x^{\prime}(0)=v_{x}(0)=V \cos \theta \\
y^{\prime}(0)=v_{y}(0)=V \sin \theta \\
x(0)=0 \\
y(0)=1 .
\end{gathered}
$$


Now Euler's method gives:

$$
F(t+\Delta t) \approx F(t)+\Delta t F^{\prime}(t)
$$

where $F(t)$ is any of the functions $x(t), y(t), v_{x}(t)$ or $v_{y}(t)$. We now use an Excel Spreadsheet solver and a guess and check method to determine the value of $\theta$, the angle above the horizontal, which causes the bullet to strike the center of the target. The Excel Spreadsheets are given in the Appendix.

\section{DISCUSSION}

In order to hit the center of the target as stated in the problem, the gun marksman will have to aim the barrel of the Remington $30-06$ rifle at $0.436^{\circ}$ above the horizontal. The result was considerably smaller than the expected $30^{\circ}$ above the horizontal. The data from the problem shows the time it took for the bullet to hit the target, the maximum height the bullet reaches while in flight and the velocity of the bullet as it hits the target. Although Euler's method only provides an approximation we believe the method is sufficient for the problem at hand, as our approximation takes air resistance into consideration.

To the problem at hand, there is a dramatic difference between methods that take into account the air resistance compared to methods that neglects the effect of air resistance. We provide Figure 1 and Figure 2 to highlight these differences in our situation. 


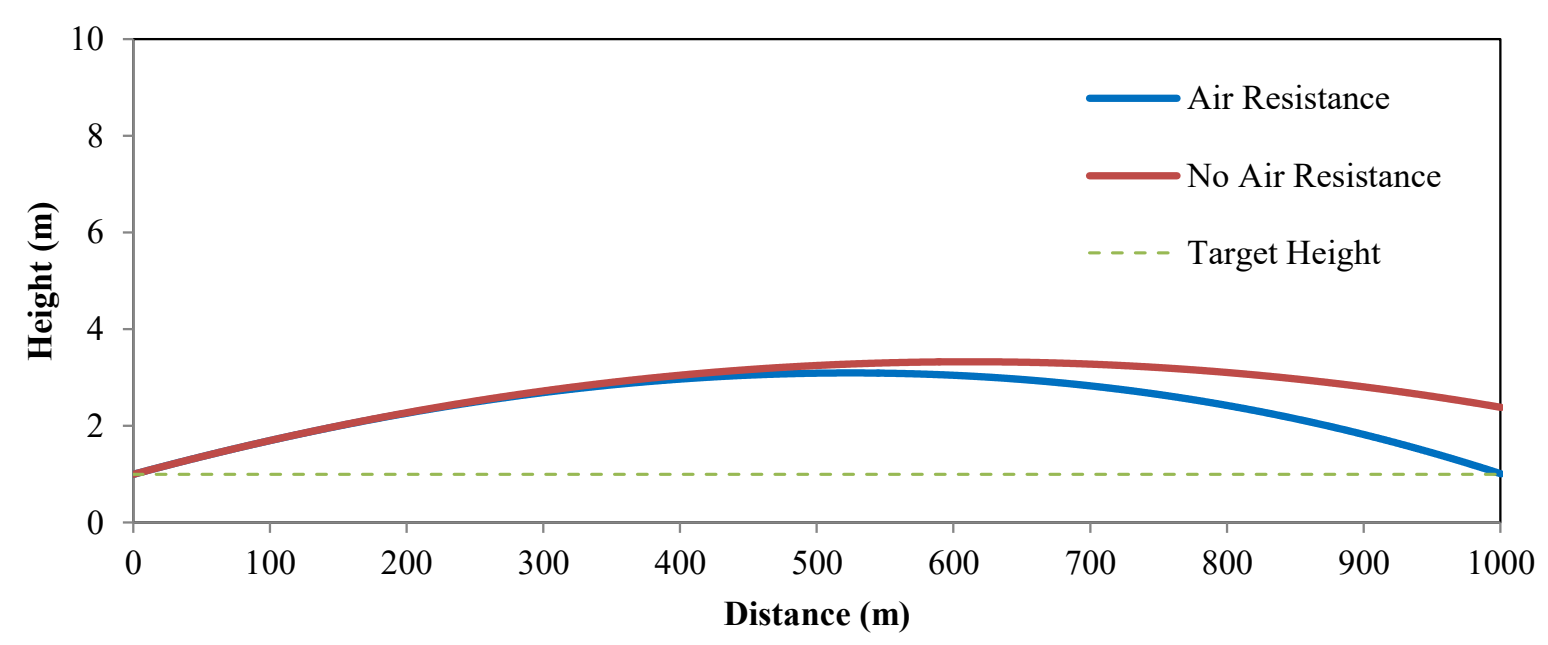

Figure 1: Trajectory of a bullet fired from a Remington 30-06 rifle at an angle of $\mathbf{0 . 4 3 6}$ above the horizontal to hit a target sitting $1 \mathrm{~m}$ off the ground $1000 \mathrm{~m}$ away.

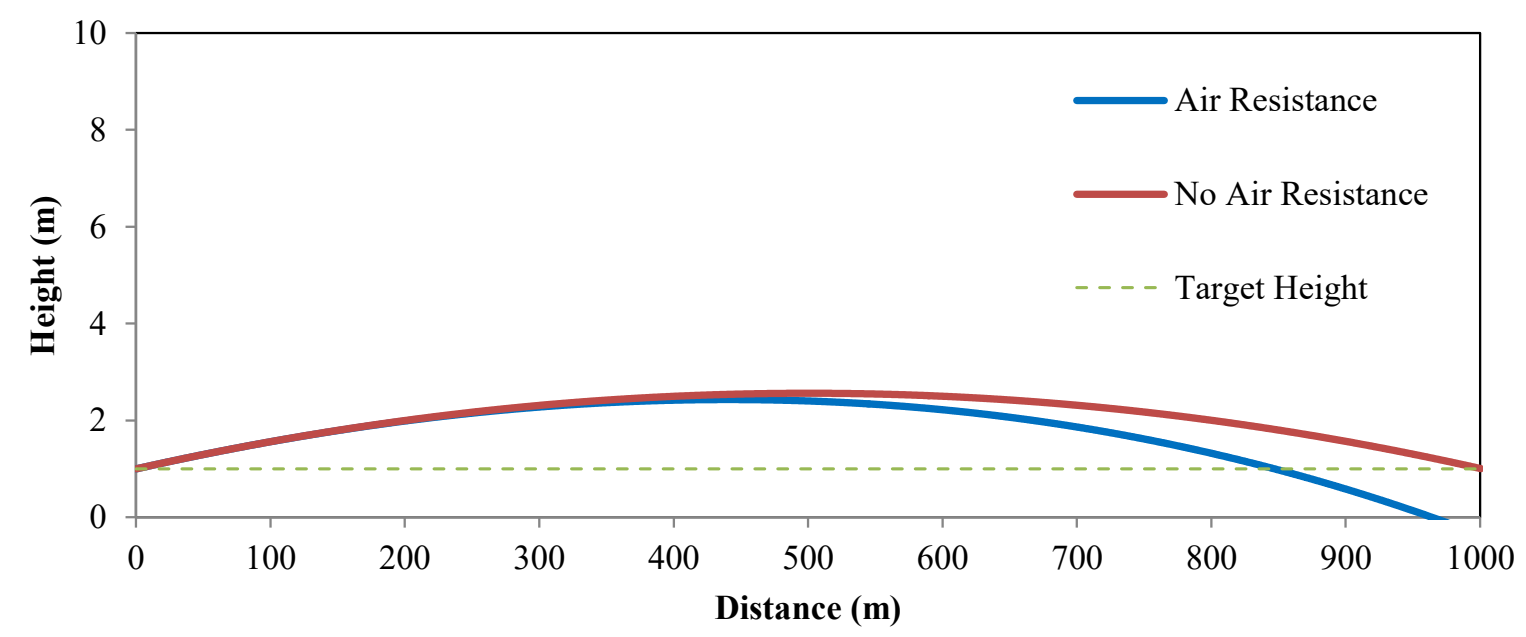

Figure 2: Trajectory of a bullet fired from a Remington 30-06 rifle at an angle of $\mathbf{0 . 3 5 7 ^ { \circ }}$ above the horizontal to hit a target sitting $1 \mathrm{~m}$ off the ground $1000 \mathrm{~m}$ away.

With air resistance the bullet launched at an angle of $0.436^{\circ}$ above the horizontal travels a little over two meters vertically and remains in flight for 1.305 seconds before striking the target. Without air resistance the rifle must be aimed $0.357^{\circ}$ above the horizontal to hit the center of the target and the bullet remains airborne for 1.128 seconds, travelling 1.5 meters vertically. 
Clearly air resistance should be considered for measuring a bullet's flight, otherwise the data will be distorted. This information is essential to engineers and scientists who develop guns, scopes, rangefinders and ammunition.

\section{CONCLUSION AND RECOMMENDATIONS}

In summary, we determined that a gun marksman has to aim the gun at $0.436^{\circ}$ to hit the center of a target $1 \mathrm{~m}$ off the ground and $1000 \mathrm{~m}$ away with an air temperature of $27.2^{\circ} \mathrm{C}$. With the results stemming from our initial assumptions known, it would be interesting to run a similar problem with different assumptions and compare results. What is the effect of a different ambient temperature, elevation, or even bullet type? For our calculations we assumed a pointed soft point bullet. Pointed soft point bullets are solid compared to hollow point bullets (see Fig. 3) that have a small hollow point. As a result of the small indentation on the tip of the bullet, it is possible that hollow point bullet shot at the target in the same conditions would have more drag and require a different launch angle to hit the center of the target.
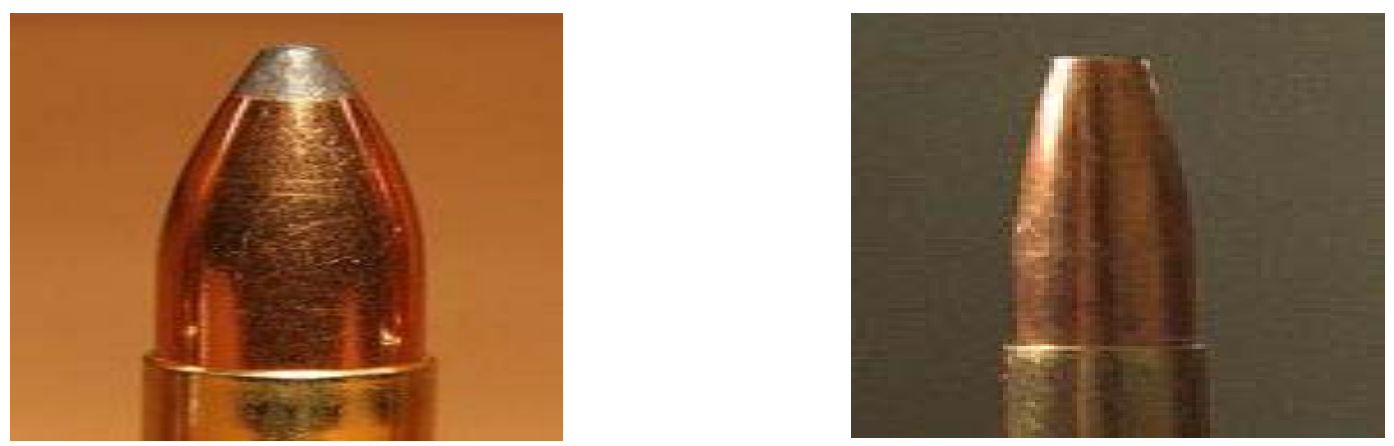

Figure 3: Comparison of soft point (left) and hollow point (right) bullets. 


\section{NOMENCLATURE}

\begin{tabular}{ccc}
\hline Symbol & Definition & Units \\
\hline $\mathrm{P}$ & Pressure & Atmospheres \\
$\mathrm{V}$ & Volume & Liters \\
$\mathrm{T}$ & Temperature & ${ }^{\circ} \mathrm{C}$ \\
$\theta$ & Angle off Horizontal & Degrees \\
$v$ & Speed & meters \\
$C$ & Drag Coefficient & second \\
$M$ & Mass & No Units \\
A & Area & Kilograms \\
$D$ & Drag & meters ${ }^{2}$ \\
\hline
\end{tabular}

\section{REFERENCES}

Larson, Ron, Robert Hostetler and Bruce Edwards. Calculus. 8th Edition. Boston, MA: Houghton Mifflin Company, 2005.

"Shape Effects on Drag." http://www.grc.nasa.gov/WWW/k-12/airplane/shaped.html. NASA, n.d. Web. 30 Nov. 2011

Campbell, Scott. Chemical Engineering, University of South Florida, Tampa, FL, Personal Communication 


\section{APPENDIX - EULER'S METHOD COMPUTATIONS}

\begin{tabular}{|c|c|c|c|c|c|c|c|c|c|c|c|}
\hline$\diamond$ & A & B & C & D & E & $F$ & G & H & I & J & K \\
\hline 1 & Thetadeg & 0.436 & & & D & 2.77E-06 & & & & & \\
\hline 2 & theta & 0.00761 & & & M & 0.00972 & & & & & \\
\hline 3 & $\mathrm{vxO}$ & 886.9743 & & & & & & & & & \\
\hline 4 & vyo & 6.749676 & & & & & & & & & \\
\hline 5 & XO & 0 & & & & & & & & & \\
\hline 6 & yo & 1 & & & & & & & & & \\
\hline 7 & & & & & & & & & & & \\
\hline 8 & t & $x$ & y & $v x$ & vy & v & $x^{\prime}$ & $y^{\prime}$ & $v x^{\prime}$ & $v y^{\prime}$ & \\
\hline 9 & 0 & 0 & 1 & 886.9743 & 6.749676 & 887 & 886.974319 & 6.749675879 & -224.2102 & -11.51 & \\
\hline 10 & 0.001 & 0.886974 & 1.00675 & 886.7501 & 6.73817 & 886.7757 & 886.750108 & 6.73816969 & -224.0968 & -11.50 & \\
\hline 11 & 0.002 & 1.773724 & 1.013488 & 886.526 & 6.726667 & 886.5515 & 886.526012 & 6.72666684 & -223.9835 & -11.50 & \\
\hline 12 & 0.003 & 2.66025 & 1.020215 & 886.302 & 6.715167 & 886.3275 & 886.302028 & 6.715167327 & -223.8704 & -11.50 & \\
\hline 13 & 0.004 & 3.546552 & 1.02693 & 886.0782 & 6.703671 & 886.1035 & 886.078158 & 6.703671148 & -223.7573 & -11.49 & \\
\hline 14 & 0.005 & 4.432631 & 1.033633 & 885.8544 & 6.692178 & 885.8797 & 885.8544 & 6.692178301 & -223.6443 & -11.49 & \\
\hline 15 & 0.006 & 5.318485 & 1.040326 & 885.6308 & 6.680689 & 885.656 & 885.630756 & 6.680688782 & -223.5313 & -11.49 & \\
\hline 16 & 0.007 & 6.204116 & 1.047006 & 885.4072 & 6.669203 & 885.4323 & 885.407225 & 6.669202591 & -223.4185 & -11.48 & \\
\hline 17 & 0.008 & 7.089523 & 1.053675 & 885.1838 & 6.65772 & 885.2088 & 885.183806 & 6.657719723 & -223.3057 & -11.48 & \\
\hline
\end{tabular}

Figure 4: Screenshot of calculations for Euler's method using Microsoft Excel.

\begin{tabular}{|c|c|c|c|c|c|c|c|c|c|c|}
\hline$\diamond$ & A & B & C & D & $E$ & $\mathrm{~F}$ & G & $\mathrm{H}$ & 1 & J \\
\hline \multicolumn{3}{|c|}{1 Thetadeg 0.436} & & & 0 & 0.00000277 & & & & \\
\hline $2 t$ & theta & $=81 / 180^{*} 3.14159$ & & & M & 0.00971984 & & & & \\
\hline $3 v$ & vXO & $=887^{*} \cos (B 2)$ & & & & & & & & \\
\hline $4 v$ & wo & $=887^{*} \operatorname{SIN}(B 2)$ & & & & & & & & \\
\hline $5 \times$ & $x 0$ & 0 & & & & & & & & \\
\hline $6 y$ & yo & 1 & & & & & & & & \\
\hline \multicolumn{11}{|l|}{7} \\
\hline $8 t$ & & $x$ & y & $v x$ & w & v & $x^{\prime}$ & $y^{\prime}$ & $v x^{\prime}$ & $w^{\prime}$ \\
\hline 90 & & $=B 5$ & $=B 6$ & $=B 3$ & $=B 4$ & $=\operatorname{SQRT}\left(\operatorname{Dg}{ }^{\wedge} 2+E g^{\wedge} 2\right)$ & $=D 9$ & $=E 9$ & $=-\$ F \$ 1 / \$ F \$ 2^{*} F 9^{*} D 9$ & $=-9.8-\$ F \$ 1 / \$ F \$ 2^{*} F 9^{*} E 9$ \\
\hline 100 & 0.001 & $=B 9+(A 10-A 9)^{*} G 9$ & $=C 9+(A 10-A 9)^{*} H 9$ & $=D 9+(A 10-A 9) * 19$ & $=E 9+(A 10-A 9) * J 9$ & $=S Q R T\left(D 10^{\wedge} 2+E 10^{\wedge} 2\right)$ & $=010$ & $=E 10$ & $=-\$ F \$ 1 / \$ F \$ 2^{*} F 10^{*} 010$ & $0=-9.8-\$ \$ \$ 1 / \$ F \$ 2^{*} F 10^{*} E 10$ \\
\hline 110 & 0.002 & $=B 10+(A 11-A 10)^{*} G 10$ & $=C 10+(A 11-A 10)^{*}+10$ & $=D 10+(A 11-A 10)^{*} \mid 10$ & $=E 10+(A 11-A 10) * 10$ & $=S Q R T\left(D 11^{\wedge} 2+E 11^{\wedge} 2\right)$ & $=011$ & $=E 11$ & $=-\$ F \$ 1 / \$ F \$ 2^{*} F 11^{*} 011$ & $1=-9.8-\$ \$ \$ 1 / \$ \$ \$ \$ 2^{*} F 11^{*} E 11$ \\
\hline 120 & 0.003 & $=B 11+(\mid A 12-A 11)^{*} G 11$ & $=C 11+(\mid 12-A 11)^{* H 11}$ & $=D 11+($ A12-A11)* $\mid 11$ & $=E 11+(\mid A 12-A 11)^{*} * 11$ & $=S Q R T\left(D 12^{\wedge} 2+E 12^{\wedge} 2\right)$ & $=012$ & $=E 12$ & $=-\$ F \$ 1 / \$ F \$ 2^{*} F 12^{*} 012$ & $2=-9.8-\$ \$ \$ 1 / \$ F \$ 2^{*} F 12^{*} E 12$ \\
\hline 130 & 0.004 & $=B 12+(\mid A 13-A 12)^{*} G 12$ & $=C 12+(\mid 13-A 12)^{* H 12}$ & $=D 12+(\mid A 13-A 12)^{*} \mid 12$ & $\left.=E 12+(\mid \mathrm{A} 13-\mathrm{A} 12)^{*}\right) 12$ & $=S Q R T\left(D 13^{\wedge} 2+E 13^{\wedge} 2\right)$ & $=013$ & $=E 13$ & $=\$ \$ \$ \$ 1 / \$ F \$ 2^{*} F 13^{*} D 13$ & $3=-9.8-\$ \$ \$ 1 / \$ F \$ 2^{*} F 13^{*} E 13$ \\
\hline 140 & 0.005 & $=B 13+(\mid 144-A 13)^{*} G 13$ & $=C 13+(\mid 144-A 13)^{* H 13}$ & $=D 13+(A 14-A 13)^{*} \| 13$ & $=E 13+(\mid 144-A 13)^{*} \mid 13$ & $=S Q R T(D 14 \wedge+E 14 \wedge 2)$ & $=014$ & $=E 14$ & $=\$ \$ \$ \$ 1 / \$ F \$ 2^{*} F 14^{*} 014$ & $4=-9.8-\$ \$ \$ 1 / \$ F \$ 2^{*} F 14^{*} E 14$ \\
\hline & & $=B 14+(\mid 115-A 14)^{*} G 14$ & $=C 14+(\mid 115-A 14)^{* H 14}$ & $=D 14+(\text { A15-A14) })^{*} 14$ & $\left.=E 14+(\mid 115-A 14)^{*}\right] 14$ & $=S Q R T\left(D 15^{\wedge} 2+E 15^{\wedge} 2\right)$ & $=015$ & $=E 15$ & $=\$ \$ \$ \$ 1 / \$ F \$ 2^{*} F 15^{*} 015$ & $5=-9.8-\$ \$ \$ 1 / \$ F \$ 2 * F 15^{*} E 15$ \\
\hline 160 & 0.007 & $=B 15+(\mid A 16-A 15) * G 15$ & $=C 15+(\mid$ A16-A15)*H15 & $=D 15+($ A16-A15)*115 & $=E 15+(A 16-A 15)^{*} 15$ & $=S Q R T\left(D 16^{\wedge} 2+E 16^{\wedge} 2\right)$ & $=016$ & $=E 16$ & $=-\$ F \$ 1 / \$ F \$ 2^{*} F 16^{*} 016$ & $6=-9.8-\$ F \$ 1 / \$ F \$ 2^{*} F 16^{*} E 16$ \\
\hline 170 & 0.008 & $=B 16+(\mid A 17-A 16) * G 16$ & $=C 16+(\mid \mathrm{A} 17-\mathrm{A} 16) * H 16$ & $=D 16+($ A17-A16)* $\mid 16$ & $=E 16+(A 17-A 16)^{*} * 16$ & $=\operatorname{SQRT}\left(D 17^{\wedge} 2+E 17^{\wedge} 2\right)$ & $=017$ & $=E 17$ & $=-\$ \$ \$ 1 / \$ F \$ 2^{*} F 17^{*} 017$ & $7=-9.8-\$ \$ \$ \$ 1 / \$ F \$ 2 * F 17^{*} E 17$ \\
\hline 180 & 0.009 & $=B 17+\mid(\mid 18-A 17)^{*} G 17$ & $=C 17+(\mid 118-A 17)^{* H 17}$ & $=D 17+(\mid \mathrm{A} 18-A 17)^{*} \mid 17$ & $=E 17+(\mid A 18-A 17)^{*} * 17$ & $=S Q R T(D 18 \wedge 2+E 18 \wedge 2)$ & $=018$ & $=E 18$ & $=\$ \$ \$ \$ 1 / \$ F \$ 2^{*} F 18^{*} 018$ & $B=-9.8-\$ F \$ 1 / \$ F \$ 2^{*} F 18^{*} E 18$ \\
\hline 190 & & $=B 18+(A 19-A 18)^{*} G 18$ & $=C 18+(A 19-A 18)^{*}+118$ & $=D 18+($ A19-A18)"18 & $=E 18+(A 19-A 18)^{*} \mid 18$ & $=\operatorname{SQRT}\left(D 19 \wedge 2+E 19^{\wedge} 2\right)$ & $=D 19=$ & $=E 19$ & $=\$ \$ \$ \$ 1 / \$ F \$ 2^{*} \mid 19^{*} 019$ & $9=-9.8-\$ \$ \$ 1 / \$ F \$ 2^{*} F 19^{*} E 19$ \\
\hline
\end{tabular}

Figure 5: Screenshot of formulas used in the calculation of Euler's method. 